\title{
Financing of mental health services: an international perspective
}

\author{
Shekhar Saxena ${ }^{1}$ and Pratap Sharan ${ }^{2}$
}

${ }^{1}$ Coordinator, Mental Health: Evidence and Research, Department of Mental Health and Substance Abuse, World Health Organization, CH - 1211, Geneva - 27, Switzerland, email saxenas@who.int

${ }^{2}$ Medical Officer, Mental Health: Evidence and Research, World Health Organization

E inancing is a critical factor in the realisation of a viable mental health system. It is the mechanism by which plans and policies are translated into action through the allocation of resources. Financing is essential for operations and the delivery of services, for the development and deployment of a trained workforce, and for the required infrastructure and technology (Chernichovsky \& C hinitz, 1995; World Health O rganization, 2003). Financing mechanisms can also be used to facilitate change and introduce innovations in systems (World Health O rganization, 2003).

\section{Financing of mental health services across countries}

The World Health O rganization, in its Project Atlas, collected information on the resources available for mental health care from 191 countries during the year 2001 (World H ealth $O$ rganization, 2001). Information related to policy, programmes, financing and mental health resource indicators (beds, personnel, services for special populations and availability of drugs) was sought from the $M$ inistry of $\mathrm{H}$ ealth of each country.

The results were worrying:

o one-third of countries did not have a specified budget for mental health

o out-of-pocket payment was the primary method of financing mental health care in one-sixth of countries (one-third of countries in the African and the South East Asia regions)

o no country in the African, South East Asia and the Western Pacific regions used social insurance as the primary method of financing mental health care.

Eighty-nine countries were able to report the mental health budget as a proportion of the overall health budget. More than one-third of these countries spent less than $1 \%$ of their total health budget on mental health (African region - 79\%, South East Asia region - 63\%). Low - and lower-middle-income countries (World Bank classification) spent a significantly smaller proportion of their health budget on mental health than did high- and higher-middle-income countries. H owever, the situation in high-income countries was not uniformly satisfactory: many spent less than $5 \%$ of their health budget on mental health.

The 89 countries were categorised into three groups - those spending less than $1 \%$, those spending $1-5 \%$ and those spending more than $5 \%$ of their health budget on mental health - which were compared in terms of policy, programme and resource indicators. The presence or absence of policies and programmes was not associated with the level of mental health financing, but the catego risation was significantly associated with the availability of disability benefits and other mental health service indicators - total number of mental hospital beds, number of mental health beds in the general health sector, number of psychiatrists, number of psychologists, number of nurses in the mental health field, services for special populations (e.g. minorities, refugees), availability of psychotropic medications and the availability of antiParkinsonian drugs (Saxena et al, 2003).

\section{Disparity between burden and resource allocation}

There is a marked disparity between the burden of mental illness and the resources allocated to its treatment and prevention: World Health O rganization (2004) data on the global burden of disease (GBD) showed that mental illness accounted for $12.9 \%$ of disability-adjusted life years (DALYs), while federal governments allocated only $3.5 \%$ of their health budgets to mental health (Saxena et al, 2003). The extent of underfunding was highlighted further by the fact that depression alone accounted for $4.4 \%$ of D ALYs worldwide (Ü stün et al, 2004).

Among the many factors that can give rise to underfunding are: poor economic conditions in countries; inadequate recognition of mental health problems and their consequences; unwillingness or inability of individuals with mental health problems (or their families) to pay for treatment; and failure by policy makers to understand what can be done to prevent or treat mental disorders, which results in a belief that funding for other services is more beneficial to society (Desjarlais et al, 1995; World Health O rganization, 2003).

\section{Financing the mental health system}

The financing of mental health services occurs in widely disparate political and economic contexts and, often, within the context of more general health care financing. The first actions required to ensure adequate financing are the building of a coalition - of policy makers, service providers, researchers, advocates and so on - and reaching a consensus on what the key needs are $(\mathrm{Hu}, 2003$;
There is a marked disparity between the burden of mental illness and the resources allocated to its treatment and prevention mental illness accounted for $12.9 \%$ of disability-adjusted life years (DALYs), while federal governments allocated only $3.5 \%$ of their health budgets to mental health.

Eighty-nine countries were able to report the mental health budget as a proportion of the overall health budget. More than one-third of

these countries spent less than 1\% of their total health budget on mental health. 
World H ealth 0 rganization, 2003). The following issues have to be addressed in financing mental health systems (World H ealth $O$ rganization, 2003):

O mobilisation of finances

O allocation to address priority needs

o controlling the cost of care.

\section{Mobilisation of finances}

\section{Out-of-pocket} payment is a greater obstacle for mental health care than it is for general health care, as individuals (and their families) with mental disorders are commonly poorer than the rest of the population and less able or willing to seek care because of stigma or previous negative experiences of services.
An important consideration in mobilising finances is the fact that out-of-pocket payment is a greater obstacle for mental health care than it is for general health care, as individuals (and their families) with mental disorders are commonly poorer than the rest of the population and less able or willing to seek care because of stigma or previous negative experiences of services (C hernichovsky \& Chinitz, 1995; McAlpine \& Mechanic, 2000; World Health $O$ rganization, 2003). However, mandatory coverage through social insurance is difficult to achieve in many systems (not necessarily only in poor countries); hence, plans that differ in terms of comprehensiveness, nature of funding, degree of federal control, involvement of insurance agencies and the degree of cost sharing between the individual and the insurer should be considered (Hu, 2003; World Health 0 rganization, 2003).

\section{Allocation to address priority needs}

The allocation of funds must be tied to policy priorities. These priorities should include policy development, planning, innovation and advocacy, in addition to services (World Health O rganization, 2003). O ne approach proposed for building community-based systems involves transferring resources from hospital-based systems; however, careful evaluation of the situation prevailing in the community is needed before hospitals are downsized (McAlpine \& Mechanic, 2000; World Health 0 rganization, 2003). D ouble funding may be needed initially in order to ensure that a community system can accommodate people discharged from hospital. Especially in countries that do not have a well articulated mental health system, it is important to ensure that the financing of mental health services is an integral component of the financing of general health services, and that specific allocations are made for mental health, albeit associated with other health initiatives. Equity in health care is a cornerstone for public financing. Information on the prevalence of mental disorders, existing resources, accessibility of services, and types and cost-effectiveness of services may be relevant to the allocation for specific subgroups (World Health O rganization, 2003).

\section{Controlling the cost of care}

Efficiency in finance and the provision of care could free resources for a higher level of care (Chernichovsky \& Chinit, 1995). This could be achieved through integration of services (Browne et al, 1999), downsizing of big hospitals (World Health $\mathrm{O}$ rganization, 2003), appropriate training of staff (Chisholm et al, 2000) and development of an infrastructure for mental health financing (World Health 0 rganization, 2003).

It has been suggested that there is a shortage of economic data, particularly from developing countries, to support discussions on mental health policy and resource allocation at national and international level. This situation has changed considerably with the WHO-CHOICE study, which showed that cost-effective interventions for psychiatric disorders exist in all sub-regions (Chisholm et al, 2004).

\section{Conclusions}

In view of the large and increasing burden of mental disorders, many countries should consider an increase in their mental health budgets to provide for necessary services, training and research. This is needed in most low- and middle-income countries, but also in some high-income countries. Countries that rely on out-ofpocket payment as the primary method of financing mental health care should consider the possibility of providing coverage under social insurance. To use resources more efficiently and judiciously, countries should support integration of services, reallocation of mental health beds and research on the financing of mental health care.

\section{References}

Browne, G., Roberts, J., Gafni, A., et al (1999) Economic evaluations of community-based care: lessons from twelve studies in O ntario. Journal of Evaluation in Clinical Practice, 5, 367385

Chernichovsky, D. \& Chinitz, D. (1995) The political economy of health system reform in Israel. Health Economics, 4, 127-141.

Chisholm, D., James, S., Sekar, K., et al (2000) Integration of mental health care into primary care. Demonstration costoutcome study in India and Pakistan. British Journal of Psychiatry, 176, 581-588.

Chisholm, D., Sanderson, K., Ayuso-Mateos, J. L., et al (2004) Reducing the global burden of depression: population-level analysis of intervention cost-effectiveness in 14 world regions. British Journal of Psychiatry, 184, 393-403.

Desjarlais, R., Eisenberg, L., Good, B., et al (1995) World Mental Health: Problems and Priorities in Low-Income Countries. New York: 0 xford University Press.

Hu, T.-W. (2003) Financing global mental health services and the role of WHO. Journal of Mental Health Policy and Economics, 6, 145-147.

McAlpine, D. D. \& Mechanic, D. (2000) U tilization of speciality mental health care among persons with severe mental illness: the roles of demographics, need, insurance and risk. Health Services Research, 35, 277-292.

Saxena, S., Sharan, P. \& Saraceno, B. (2003) Budget and financing of mental health services: baseline information on 89 countries from WHO's Project Atlas. Journal of Mental Health Policy and Economics, 6, 135-143.

Üstün, T. B., Ayuso-Mateos, J. L., Chatterji, S., et al (2004) Global burden of depressive disorders in the year 2000 . British Journal of Psychiatry, 184, 386-392.

World Health Organization (2001) Atlas. Mental Health Resources in the World 2001. Geneva: WHO.

World Health Organization (2003) Mental Health Financing: Mental Health Policy and Service Guidance Package. Geneva: WHO

World Health Organization (2004) The World Health Report 2004. Changing History. Geneva: WHO. 